\title{
Fish under exercise
}

\author{
Arjan P. Palstra $\cdot$ Josep V. Planas
}

Received: 4 February 2011 / Accepted: 14 February 2011/Published online: 25 May 2011

(C) The Author(s) 2011. This article is published with open access at Springerlink.com

\begin{abstract}
Improved knowledge on the swimming physiology of fish and its application to fisheries science and aquaculture (i.e., farming a fitter fish) is currently needed in the face of global environmental changes, high fishing pressures, increased aquaculture production as well as increased concern on fish wellbeing. Here, we review existing data on teleost fish that indicate that sustained exercise at optimal speeds enhances muscle growth and has consequences for flesh quality. Potential added benefits of sustained exercise may be delay of ovarian development and stimulation of immune status. Exercise could represent a natural, noninvasive, and economical approach to improve growth, flesh quality as well as welfare of aquacultured fish: a FitFish for a healthy consumer. All these issues are important for setting directions for policy decisions and future studies in this area. For this purpose, the FitFish workshop on the Swimming
\end{abstract}

A. P. Palstra $(\bowtie) \cdot$ J. V. Planas $(\bowtie)$

Departament de Fisiologia, Facultat de Biologia,

Universitat de Barcelona and Institut de Biomedicina de la

Universitat de Barcelona (IBUB), Av. Diagonal 645,

08028 Barcelona, Spain

e-mail: arjan.palstra@wur.nl

J. V. Planas

e-mail: jplanas@ub.edu

Present Address:

A. P. Palstra

Institute for Marine Resources and Ecosystem Studies

(IMARES) of the Wageningen University, P.O. Box 77,

4400 AB Yerseke, The Netherlands
Physiology of Fish (http://www.ub.edu/fitfish2010) was organized to bring together a multidisciplinary group of scientists using exercise models, industrial partners, and policy makers. Sixteen international experts from Europe, North America, and Japan were invited to present their work and view on migration of fishes in their natural environment, beneficial effects of exercise, and applications for sustainable aquaculture. Eighty-eight participants from 19 different countries contributed through a poster session and round table discussion. Eight papers from invited speakers at the workshop have been contributed to this special issue on The Swimming Physiology of Fish.

Keywords Locomotion Aquaculture - Welfare . Health · Muscle growth · Reproductive homing migration · Energy metabolism · Biomechanics

\section{Introduction}

For most teleost fish species, swimming is an important aspect of their life history in the aquatic environment. Teleost fish show a great variety of locomotor strategies, mostly exemplified by their ability to undergo extensive reproductive and feeding migrations. However different these strategies may be, swimming is intimately related to important biological processes taking place in the organism, such as early development, somatic growth, gonadal growth, and maturation. From a physiological point 
of view, however, remarkable gaps exist in our knowledge on the effects of swimming in teleost fish. Nevertheless, existing data on several species of teleost fish indicate that the induction of sustained exercise may result in higher growth rates, higher skeletal muscle mass, reduced aggressive interactions, and increased survival. Furthermore, potential added benefits of sustained exercise may be the delay of ovarian development and possibly also the stimulation of immune function. Exercise could represent a natural, noninvasive, and economical approach to improve growth, flesh quality as well as welfare of aquacultured fish: A FitFish for a healthy consumer.

The purpose of the FitFish Workshop on the Swimming Physiology of Fish that we organized in Barcelona, Spain (July 2-3, 2010), was to strengthen scientific knowledge and provide relevant scientific information on fish swimming. Swimming exercise was taken as a central theme to bring together researchers that use swimming from the different angles of (eco)physiology, experimental zoology, immunology, reproductive endocrinology, fish migration, transcriptomics, behavioral biology, biomechanics, and other fields in fish biology following a multidisciplinary approach.

This special FISH issue presents selected papers based on invited communications presented at the workshop. In this paper, we will introduce this special issue by shortly reviewing the effects of swimming exercise on muscle growth and flesh quality and on sexual maturation and reproduction. An overview of contributions of invited speakers is presented followed by an introduction of the selected papers for this special issue.

\section{Effects of swimming exercise on muscle growth and flesh quality}

Teleost fish are known for their great capacity for aerobic, sustained swimming, and anaerobic, burst swimming. Swimming activity in fish is accomplished through the activation of the skeletal muscle, the largest tissue in the animal representing more than $50 \%$ of its body weight. Skeletal muscle in fish is composed of two functionally and anatomically separated types of muscle: white and red muscle. White muscle represents the bulk of the skeletal muscle (approximately 95\% of the total muscle mass), is composed of anaerobic, glycolytic fibers, and supports burst or high-speed swimming (e.g., escape reactions). In contrast, red muscle is a minor part of the skeletal muscle located on the surface of the trunk of the fish along the lateral line, is composed of aerobic, oxidative fibers, and supports sustained swimming (Altringham and Ellerby 1999). Although it is generally considered that only red fibers are recruited during sustained swimming, white fibers may also be recruited to a lesser extent (reviewed in Johnston 1999).

\section{Effects of swimming exercise on growth}

In salmonid fish, the stimulatory effects of moderate sustained swimming on growth were initially shown more than 30 years ago. Brook trout (Salvelinus fontinalis) swimming at speeds of $0,0.85,1.72$, and 2.5 body lengths per second (BL/s) experienced increases in length $(1,3.5,0.5$, and $0.7 \%$, respectively) as well as weight $(24,34,16$, and $17 \%$, respectively), indicating that growth was highest at intermediate swimming speeds (e.g., $0.85 \mathrm{BL} / \mathrm{s}$ ) (East and Magnan 1987). Davison and Goldspink (1977) performed similar tests with brown trout (Salmo trutta) and found maximal growth at $1 \mathrm{BL} / \mathrm{s}$. Similarly, maximal growth was obtained in rainbow trout (Oncorhynchus mykiss) at a swimming speed of $1 \mathrm{BL} / \mathrm{s}$ (Greer Walker and Emerson 1978). Furthermore, Atlantic salmon (Salmo salar) raised in raceways and exposed to long-term sustained swimming showed a $38 \%$ increase in growth with respect to the non-exercised fish (Totland et al. 1987). Therefore, for all salmonid species examined to date, the induction of moderate, sustained exercise results in a significant increase in body weight, indicating that exercise potentiates growth. Much less information is available on the potential stimulatory effects of swimming exercise in non-salmonid species. For example, a recent study showed that swimming exercise stimulates growth in seabream (Sparus aurata) (Ibarz et al. 2011), supporting the idea that the growth stimulatory effects of exercise may be widespread among fish species that experience swimming as part of their natural behavior.

Although a limited amount of information is available on the mechanism(s) by which exercise may potentiate growth in fish, current evidence suggests that quantitative and qualitative changes in 
skeletal muscle are responsible for the increase in growth. Fish skeletal muscle has been shown to undergo structural (e.g., myotomal muscle structure), morphometric (e.g., fiber density and size), and biochemical (e.g., enzyme activities) changes in response to exercise (Johnston and Moon 1980; Davison 1997). In particular, exercise has been shown to stimulate hypertrophy of muscle fibers, evidenced by the presence of a higher proportion of large fibers in muscle from exercised fish (Davison 1997; Johnston 1999; Johnston and Moon 1980; Bugeon et al. 2003). However, it is not yet well established if sustained exercise affects fiber recruitment (hyperplasia), which is the process by which the total number of muscle cells is established (Johnston 1999). A study comparing muscle cellularity between farmed and wild sea bass suggested that the higher white muscle fiber density of wild fish may have been determined by the higher exercise levels experienced by wild over farmed fish (Periago et al. 2005). Therefore, the increase in the somatic growth of exercised fish is due in part to changes in the cellularity of skeletal muscle. As will be indicated below, changes in cellularity will contribute to changes in the quality of the skeletal muscle and since this tissue is the part of the fish destined for human consumption, it may have important economical consequences.

In addition to morphological changes, important biochemical changes take place in the skeletal muscle in response to exercise. Since exercise is the result of the increase in contractile activity by the working muscle, an increase in overall energy expenditure and, in particular, skeletal muscle fuel uptake and utilization are expected. In general, adaptation to sustained exercise is characterized by an increase in the aerobic capacity of the red skeletal muscle, which confers a biochemical advantage due to the high energy yield of oxidative pathways (Weber and Haman 1996). Under sustained swimming, it is known that red muscle contraction is fueled by ATP generated by oxidation mostly of lipid and carbohydrate substrates (Moyes and West 1995). Although lipids are usually considered the primary fuel used during prolonged exercise, recent estimates of fuel utilization indicate that sustained swimming is supported by the oxidation of approximately $45 \%$ carbohydrate, $35 \%$ lipid, and $20 \%$ protein in the red muscle of rainbow trout (Richards et al. 2002). Interestingly, exercise is known to cause a
28 -fold increase in glucose utilization in the rainbow trout red muscle, but not in white muscle (West et al. 1993). The stimulatory effects of exercise on glucose utilization are important in light of (1) the known poor ability of fish peripheral tissues to clear a glucose load from the circulation, prompting some authors to consider that teleost fish are glucose intolerant (Wilson 1994; Moon 2001) and (2) the fact that commercial diets available today for carnivorous fish can contain as much as $33 \%$ carbohydrates. In mammals, exercise has a clear effect in lowering plasma glucose (Holloszy 2005), with skeletal muscle playing a key role in glucose homeostasis (Jessen and Goodyear 2005). In mammals, exercise stimulates glucose uptake in skeletal muscle by stimulating the translocation of the glucose transporter GLUT4 from intracellular stores to the plasma membrane in an insulin-independent manner (Dohm 2002). It has been proposed that AMP-activated protein kinase (AMPK) could be one of the possible mediators of the stimulatory effects of exercise on GLUT4. AMPK is considered an important sensor of cellular energy charge because exercise induced increases in AMP/ ATP and creatine/phosphocreatine ratios result in the activation of AMPK via allosteric modification and phosphorylation of the enzyme (Hardie et al. 1998). Furthermore, experiments in rat skeletal muscle show that infusion of a AMPK agonist produces an increase in glucose transport analogous to the effect of contraction (Merrill et al. 1997). Despite the physiological importance of exercise in the modulation of glucose transport in skeletal muscle, the exact mechanism(s) mediating this effect have not been entirely characterized in mammals or in other vertebrates. Preliminary evidence suggests that AMPK agonists directly stimulate AMPK activity, glucose uptake, and GLUT4 expression in trout muscle cells in primary culture (Magnoni and Planas, unpublished observations), supporting the idea that AMPK activation through exercise induction could stimulate mechanisms regulating the entry of glucose into skeletal muscle.

Effects of swimming exercise on flesh quality

Flesh quality in fish is the result of a combination of characteristics of skeletal muscle, which include the muscle chemical composition (fat content and fatty acid profile, glycogen stores, oxidative stability, 
color) and muscle cellularity (Johnston 1999) and is strongly influenced by a variety of extrinsic factors such as feeding, pre- and post-slaughter handling, processing, and storage procedures. One of the major criteria of flesh quality is texture, which is determined by muscle cellularity (fiber number and distribution) and connective tissue characteristics (total collagen content and collagen cross-linking) (Johnston 1999; Kiessling et al. 2005; Hagen et al. 2007). Collagen is the major component of connective tissue and is important for conferring the functional and rheological properties of the flesh (Bugeon et al. 2003). The mechanical strength of the connective tissue is largely determined by the cross-linking between adjacent collagen and elastin molecules and the concentration of pyridinoline cross-links (Periago et al. 2005). In fish, flesh softening has been related to the increased solubility of type V collagen (Consuegra and Johnston 2006). In salmonid species, such as Atlantic salmon and brown trout, the induction of exercise improves the textural characteristics of the flesh (Totland et al. 1987; Bugeon et al. 2003). Furthermore, the fatty acid profile of the flesh of chinook salmon (O. tshawytscha) was shown to be altered by exercise (Kiessling et al. 2005). However, no information is available on the effects of exercise on flesh quality in rainbow trout, a species with high commercial interest. Overall, the induction of exercise could represent a way to control and improve flesh quality through farming methods.

\section{Effects of swimming exercise on reproduction}

The study of reproductive migration is the area where physical fitness and Darwinian fitness meet. Animals must optimize their physical fitness to be able to reach a suitable reproductive habitat at the time when reproductively active conspecifics are present and also be able to produce and release high-quality gametes. Many fish species migrate long distances to the spawning grounds. Extreme examples are the temperate eel species of the genus Anguilla $(2,000-6,000 \mathrm{~km})$ and salmonid species of the Salmo and Oncorhynchus genus (up to $3,000 \mathrm{~km}$ ). Longdistance migrant species are often commercially interesting and very vulnerable to anthropogenic factors. Long-distance migration may include semelparity, a once-in-a-lifetime reproduction and most of the available energy is required to fuel migration and sexual maturation. Semelparous species are characterized by a very specific timing when they stop eating, start swimming, and proceed with their sexual maturation. After the definite start of migration, the quantity and quality of the energy reserves will determine whether the outcome is successful.

For long-distance migrants, a state of exercise should be considered as the optimal metabolic condition for providing the essential ingredients for the development of high-quality gametes. Several recent studies report on the interaction between metabolism and sexual maturation in wild chum salmon (Oncorhynchus keta Walbaum) (Onuma et al. 2009a, b, c) just before their spawning migration and in wild sockeye salmon (Oncorhynchus nerka Walbaum) during their spawning migration (Miller et al. 2009). However, it is difficult to assess the effects of the metabolic status in field studies because of the influence of other factors that are involved during certain stages of migration (e.g., starvation, osmoregulation, pheromones, temperature, pressure, specific cues of the spawning ground) that cannot be separated from the specific effects of exercise (also Palstra et al. 2010a). In studies on European eel and rainbow trout, exercise, such as performed by migratory fish species, has been used experimentally to study its effects on the onset of sexual maturation.

Studies on European eel, recently reviewed by Palstra et al. (2009) and Palstra and van den Thillart (2010), revealed that swimming in freshwater stimulates the early development of the oocytes (Palstra et al. 2007). Lipid mobilization induced by swimming is a requirement for the natural incorporation of lipid droplets in the oocytes. Swimming in seawater, however, suppresses the following stage of sexual maturation (i.e., hepatic vitellogenesis), which may imply that in nature eels undergo vitellogenesis and final maturation near or at the spawning grounds (Palstra et al. 2010b). During oceanic migration, females may thus remain in a prepubertal stage by dopaminergic inhibition of pituitary activity (Weltzien et al. 2009). In contrast, male eels that swam showed a twofold to threefold higher expression of luteinizing hormone $\beta$ subunit, a threefold to fivefold higher gonadosomatic index and induced spermatogenesis when compared with resting eels (Palstra et al. 2008a), suggesting that dopaminergic inhibition of sexual maturation is not effective in males. The eel 
is a very appropriate model to study metabolic and hormonal switches that trigger sexual maturation. Unfortunately, not many of the required molecular or genomic tools and resources that exist for other species that serve as physiological models (e.g., salmonid species) are available for the eel. Because of this, genomic studies have been performed in the rainbow trout as a (facultative) salmonid migrant. As in female eels, swimming exercise suppressed oocyte development in trout, possibly by inhibiting vitellogenin uptake (Palstra et al. 2010a). A swimminginduced ovarian developmental suppression at the start of vitellogenesis during long-term reproductive migration may be a strategy to avoid increased drag resistance due to oocyte growth and precocious muscle atrophy. What we have shown in rainbow trout, and in the previous studies on European eels, is that the onset of vitellogenesis is a clear suppression point and an example of phenotypic plasticity during long-distance reproductive migrations. It thus appears that the physiological processes occurring in the muscle and ovary are conflicting. When there is a need to migrate, energetic processes in the muscle that provide fuel for contraction and for muscle growth are up-regulated and those in the ovary are down-regulated. When there is a need to start vitellogenesis, the situation in muscle and ovary is reversed. A reproductive delay, as induced by exercise, may extend the period of growth and prevent the occurrence of precocious sexual maturation. Swimming exercise may thus represent a way to significantly control puberty in farmed fish (Taranger et al. 2010), at least among female migrant anguillids and salmonids.

\section{FitFish Workshop on the Swimming Physiology of Fish}

From the reviewed research under the previous section, we can conclude that exercise may represent a natural, noninvasive, and economical approach to improve muscle growth and flesh quality and extend the growth stage by delaying the onset of reproduction. All these aspects could represent major benefits for aquaculture, but it is clear that additional research efforts are needed (1) to study the functional mechanisms behind these effects, (2) to design optimal exercise protocols for specific species and conditions, and (3) to explore the feasibility for application of exercise enhancement in aquaculture. Besides the reviewed beneficial exercise effects, additional benefits may include improved health by enhancing the immune status, reduced aggressive interactions (Adams et al. 1995), increased survival (Totland et al. 1987; Takle et al. 2010), and stimulation of neurogenesis and spatial learning capacity (Huntingford 2010).

All these issues are important for setting directions for future studies in this area and for policy decisions. For this purpose, the FitFish workshop was organized to bring together a multidisciplinary group of scientists using exercise models, industrial partners, and policy makers. Sixteen international experts from Europe, North America, and Japan were invited to present their work and view on migration of fishes in their natural environment, beneficial effects of exercise, and applications for sustainable aquaculture. Eighty-eight participants from 19 different countries (Fig. 1) contributed through a poster session and round table discussion. At the time of writing, the FitFish website (http://www.ub.edu/fitfish2010), which includes the abstract book, counts close to 15,000 hits. The following section represents the various sessions of the workshop in which we will shortly summarize the discussed investigations.

\section{Swimming in a natural environment}

Salmonid and anguillid fish species show amazing abilities for long-distance migration to the spawning grounds and are anadromous and catadromous, respectively. Over recent years, integrative approaches combining biotelemetry, measurements of hormone profiles, and electrophysiological, behavioral, and molecular biological techniques to study olfactory functions have been conducted to reveal the physiological mechanism of salmonid homing migration in the natural environment (Ueda 2010, 2011). These studies revealed that homing chum salmon in the oceanic phase swim for 67 days in a straight distance of $2,760 \mathrm{~km}$ at an average swimming speed of $62 \pm 12 \mathrm{~cm} / \mathrm{s}$, at a depth of $10.4 \pm 14.7 \mathrm{~m}$, and at a temperature of $9.2 \pm 0.2^{\circ} \mathrm{C}$. Sensory manipulated experiments in lacustrine salmon populations indicated that neither magnetic nor visual cues but, instead, olfactory cues play an important role during 
Fig. 1 Demographics of participants. The 88 participants of the FitFish workshop came from 19 different countries

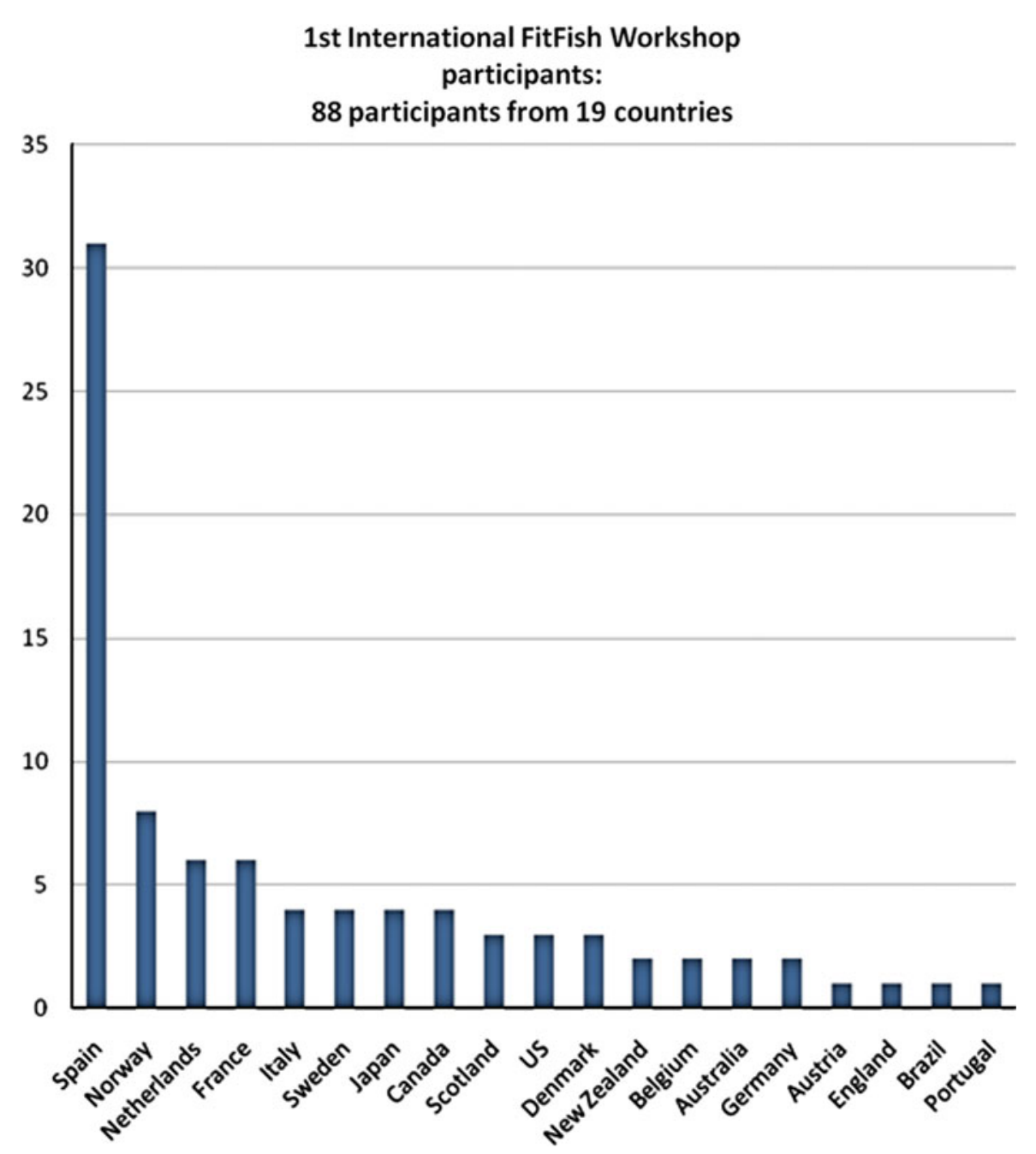

the migrational stage in freshwater. Most interestingly, sGnRH levels in the telencephalon and serum testosterone levels in both sexes showed a coincident peak at the branch point with the river that led to the spawning grounds. These results confirm that $\mathrm{sGnRH}$, besides regulating gonadotropin secretion in the pituitary, plays an olfactory role in chum salmon. This strongly suggests a functional link between olfaction and reproductive regulation with $\mathrm{sGnRH}$ as interactor. In the search for the olfactory discriminating ability of natal stream odors, glutathione S-transferase, class pi enzymes, salmon olfactory marker protein, salmon olfactory imprinting-related gene, and olfactory receptors have been identified as potential factors involved in this process. Investigations that aim to determine the triggering mechanisms of the shift from feeding migration to spawning migration and the interaction between olfaction and sexual maturation could raise important information for the control of breeding in captivity.

More difficult to study because of their catadromous life style are the anguillids. The six temperate eel species show semelparous oceanic spawning migrations of $2,000-6,000 \mathrm{~km}$. They show daily vertical migrations from a depth of $200 \mathrm{~m}$ during the night up to $600 \mathrm{~m}$ during the day and over time diving deeper and deeper to depths of $1,000 \mathrm{~m}$ (Aarestrup et al. 2009). Pressure (Sébert et al. 2007), light (Sébert et al. 2008), and temperature fluctuations (Jellyman and Tsukamoto 2010), in addition to exercise itself (Palstra and van den Thillart, 2010), have effects on sexual maturation. The initial results of the EELIAD project (Righton et al. 2010; www.eeliad.com) using miniaturized pop-up 
satellite archival transmitters and archival tags revealed that European eels swam over 2,000 km in 5 months in the direction of the Sargasso Sea. The drag resistance of the tags was discussed at the workshop and is under current investigation. Like for salmon, tracking studies on eels will provide a valuable insight into the mechanisms controlling reproduction, which will be of importance for aquaculture.

\section{Energy metabolism in swimming fish}

Laboratory studies (Fig. 2) have been instrumental for acquiring knowledge on the swimming energetics of migrating eels (Van den Thillart, 2010) and the effects of high pressure on muscle metabolism (Sébert 2010). From a biomechanical point of view, eels are inefficient swimmers (Lighthill 1970), which is hard to comprehend when their $5,500 \mathrm{~km}$ reproductive migration is considered. Migrating silver eels do not feed and therefore rely entirely on their energy reserves to fuel migration. Swimming trials performed in 22 swim tunnels (Fig. 2) have elucidated that European female eels are able to swim the full migrational distance without eating at a cost of 10-12 mg fat $/ \mathrm{km}$, which is 4-6 times more efficient than salmonids (van Ginneken et al., 2005). The total energy costs of migration and sexual maturation correspond to $67 \%$ of the fat stores (Palstra and van den Thillart 2010). During long-distance swimming, the body composition stays the same showing that energy consumption calculations cannot be based on fat alone but need to be compensated for protein oxidation. The optimal swimming speed is $0.61-0.67 \mathrm{~m} \mathrm{~s}^{-1}$ (Palstra et al. 2008b), which is $60 \%$ higher than the generally assumed cruise speed of $0.4 \mathrm{~m} \mathrm{~s}^{-1}$, implying that female eels may reach the Sargasso Sea in 3.5 months instead of the assumed 6 months. The much smaller males, however, appear to have a problem to arrive in time, which is under current investigation. Experiments on resting eels under high pressure in a hyperbaric chamber show that males have higher energy metabolism sensitivity at lower temperatures and could thus migrate deeper (Scaion and Sébert 2008). Furthermore, swimming experiments have shown that male swimming efficiency increases under pressure (Sébert et al. 2009).

How is metabolism fueled during exercise in fish? In contrast to mammals that respond to exercise by increasing the use of glucose and nonesterified fatty acids, fish utilize lipids that are provided to the contracting muscle in the form of lipoproteins (Weber 2010). In order to assess the effects of stressors like swimming and hypoxia on fish, concentration measurements do not suffice and metabolic fluxes need to be monitored (Weber 2010). An example of this can be found in schools of fish where oxygen saturation can decrease to significant degrees along the school (McFarland and Moss 1967; Steffensen 2010). This is an important aspect to keep in mind when exercise at high densities under aquaculture conditions is considered.

\section{Physiological adaptations to exercise}

Norwegian projects aim to use exercise to improve robustness of farmed Atlantic salmon (Takle et al. 2010). Challenge tests are designed to quantify cardiovascular and respiratory performances as indicators of physical fitness (Claireaux 2010). Training protocols of various intensities have been tested for their beneficial effects on performance and robustness to explore the possibilities of exercise as a preventive health measure (Takle et al. 2010). In parallel, oligonucleotide microarrays and bioinformatics systems have been developed to assess the beneficial effects of exercise at a molecular level in a highthroughput manner (Krasnov et al. 2010). Similarly, microarray analyses have been performed to investigate the effects of sustained exercise on sexual maturation in laboratory studies that aimed to mimic the early stages of reproductive migration (Palstra et al. 2010a, c). Furthermore, deep RNA sequencing of the red and white skeletal muscle of exercised and non-exercised rainbow trout has been performed to quantify exercise effects and identify novel expressed genes. By delaying sexual maturation, swimming exercise may represent a natural way to extend the feeding stage in aquaculture.

Zebrafish is increasingly receiving attention as a model fish for aquaculture. Besides having a comprehensive genomic database and transparent larvae that facilitate in vivo observations, this species offers great opportunities for large-scale testing in smallscale settings. The developing zebrafish has been used as model organism in studies on fish respiration and metabolic activity, and the effects of hypoxia and 
Fig. 2 Experimental swimming facilities. Swimming in the experimental facilities of the Leiden University (The Netherlands) with large silver eels in a setup of 22 swim tunnels (top left; van den Thillart et al. 2004), a 6,000 1 swim gutter (bottom left; Palstra et al. 2008a, 2010b), 2 small swim tunnels (top right), and a large-scale experiment with zebrafish (Palstra et al. 2010d)
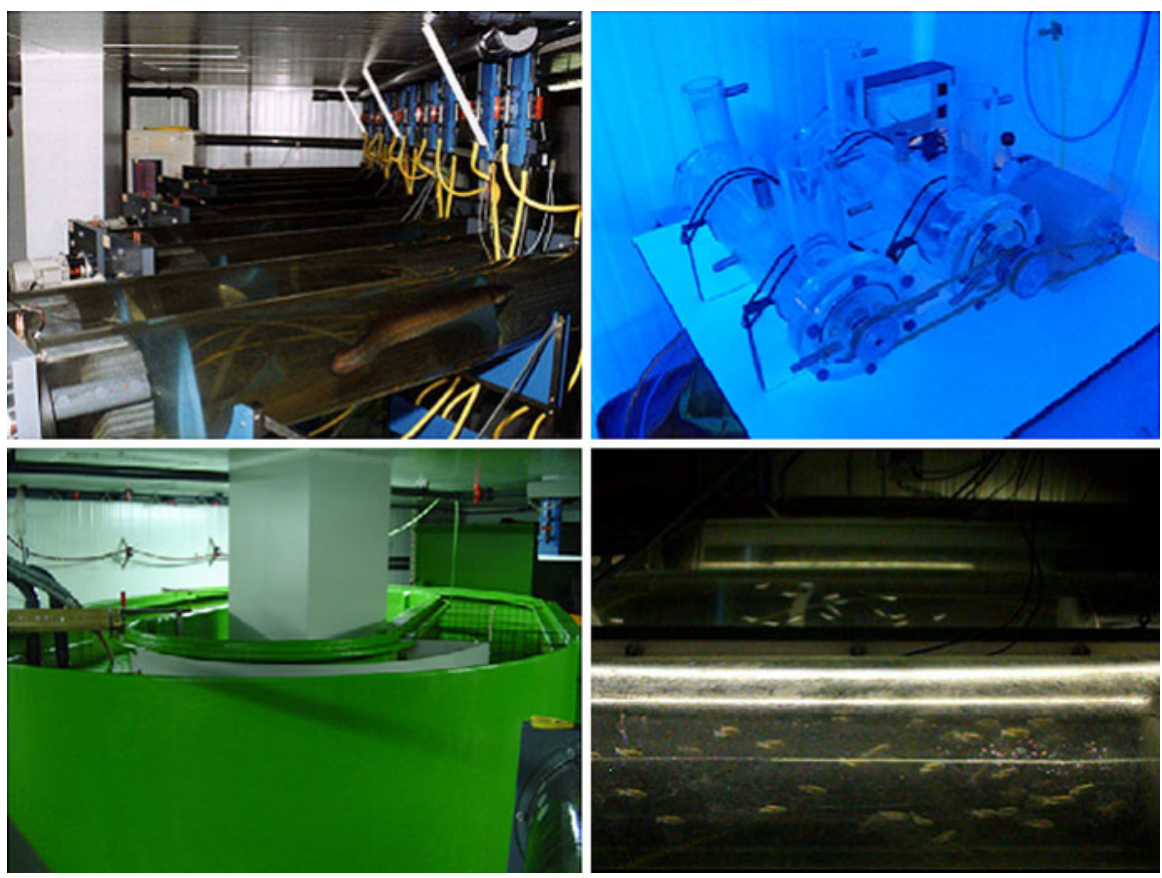

temperature have been investigated (Pelster and Bagatto 2010). Within this perspective, adaptations in the cardiovascular system, muscle tissue development, and metabolic capacities have been studied by exercising larvae (Pelster 2010). Swimming led to increased performance, mitochondrial density, and muscle tissue capillarization. Differential expression of genes related to the circadian clock in trained larvae revealed that repeated exercise may have a Zeitgeber function.

Recent studies on the swimming economy and on the effects of swimming on growth and expression of muscle growth marker genes in adult zebrafish have established this species as a useful exercise model (Palstra et al. 2010d). Zebrafish can swim at very high optimal speeds of $13.0 \mathrm{BL} \mathrm{s}^{-1}$, corresponding to $72.26 \pm 0.29 \%$ of $\mathrm{U}_{\text {crit }}$ (Tudorache et al. 2010a; Palstra et al. 2010d). Adult zebrafish that were exercised for 20 experimental days at optimal swimming speeds showed a highly significant exerciseinduced growth of $5.6 \%$ in body length and $41.1 \%$ in body weight when compared to resting fish. Expression analysis revealed clear regulatory roles for genes such as growth hormone receptor b $(g h r b)$, insulinlike growth factor 1 receptor a (igflra), troponin $\mathrm{C}$ (stnnc), slow myosin heavy chain 1 (smyhcl), troponin I2 (tnni2), myosin heavy polypeptide 2 (myhz2), and myostatin (mstnb) (Palstra et al. 2010d). We are currently performing high-throughput analyses that may be instrumental in elucidating the molecular and cellular changes taking place in muscle in response to exercise.

\section{Biomechanics of fish swimming}

The developing zebrafish is also used in biomechanical studies that aim to unravel the structural requirements that enable the mechanical performance and feedback controlling structural development (Kranenbarg et al. 2010). Early developing zebrafish show major differences between cardiac and axial muscle in response to exercise. Cardiac muscle appeared to shift to a faster phenotype, while axial muscle tended to shift toward a slow aerobic phenotype by exercise training (Van der Meulen et al. 2006).

As for aquaculture purposes, it is important to consider that the altering muscle phenotypes as a result of a specific exercise protocol may have consequences on the composition and quality of the white muscle as the final target for human consumption. If exercise protocols need to be developed that specifically aim to increase the quantity of white muscle, some authors suggest that sprint protocols would better fit the purpose than induced sustained 
swimming (Videler 2010). Possibilities for a more general ecological approach to improve fitness in fish in aquaculture were explored by Videler (2010), also in a paper in this special issue (Videler 2011).

Implementing exercise protocols in current aquaculture practices would imply adaptations to existing water flow systems. Turbulence, as experienced by cultured fish in ponds, recirculation systems, raceways, and cages, has usually negative impacts at low and at high levels. Less negative effects and even sometimes positive effects occur at intermediate levels (Webb 2010). Negative effects are associated with altering stability and positive effects promote drafting and station holding.

\section{Swimming in aquaculture}

In aquaculture, rearing conditions consisting in the confinement of cultured fish in tanks, raceways, or cages alter the natural swimming behavior of fish (Fig. 3). The change in exercise conditions under confinement is quite evident in salmonid species, such as salmon and trout, which usually experience higher water flow rates in the wild and adjust their swimming activity accordingly. Therefore, the exercise levels of captive fish are generally lower than those of wild fish, reflecting the fact that cultured trout has a decreased swimming capacity compared to wild fish (Duthie 1987). However, trout, like all fish species, can be forced to swim against a water current by increasing the water flow. Furthermore, conditions other than water flow rates in aquaculture may have a significant impact on swimming capacities. Non-optimal temperatures significantly reduce swimming characteristics such as gait transition and maximum acceleration of burst in brook charr (Salvelinus fontinalis) (Tudorache et al. 2010a, b). Increased ammonia concentrations reduced swimming capacity above gait transition speeds. Tests such as those described by Tudorache et al. (2010a, b) may be useful to establish threshold values for aquaculture management. Other parameters that can potentially impact aquaculture practices may include nitrate, nitrite, $\mathrm{pH}$, hypoxic, and hyperoxic conditions, etc.

Exercise-induced growth is optimal at specific speeds, most likely near optimal swimming speeds where the cost of transport is lowest and the energetic efficiency highest. Studies in brook charr showed that preferred swimming speeds, the speeds at which fish swim volitionally, resemble optimal swimming speeds (Tudorache et al. 2010a, b; this special issue). At swimming speeds lower than $\mathrm{U}_{\text {opt }}$, a substantial amount of energy is lost due to higher spontaneous activity (e.g., aggression), while at speeds higher than
Fig. 3 Swimming in fish farms. Fish in aquaculture often experience too high densities or too low streams to be able to swim in sea cages (top left), raceways (bottom left), or circular tanks (right)
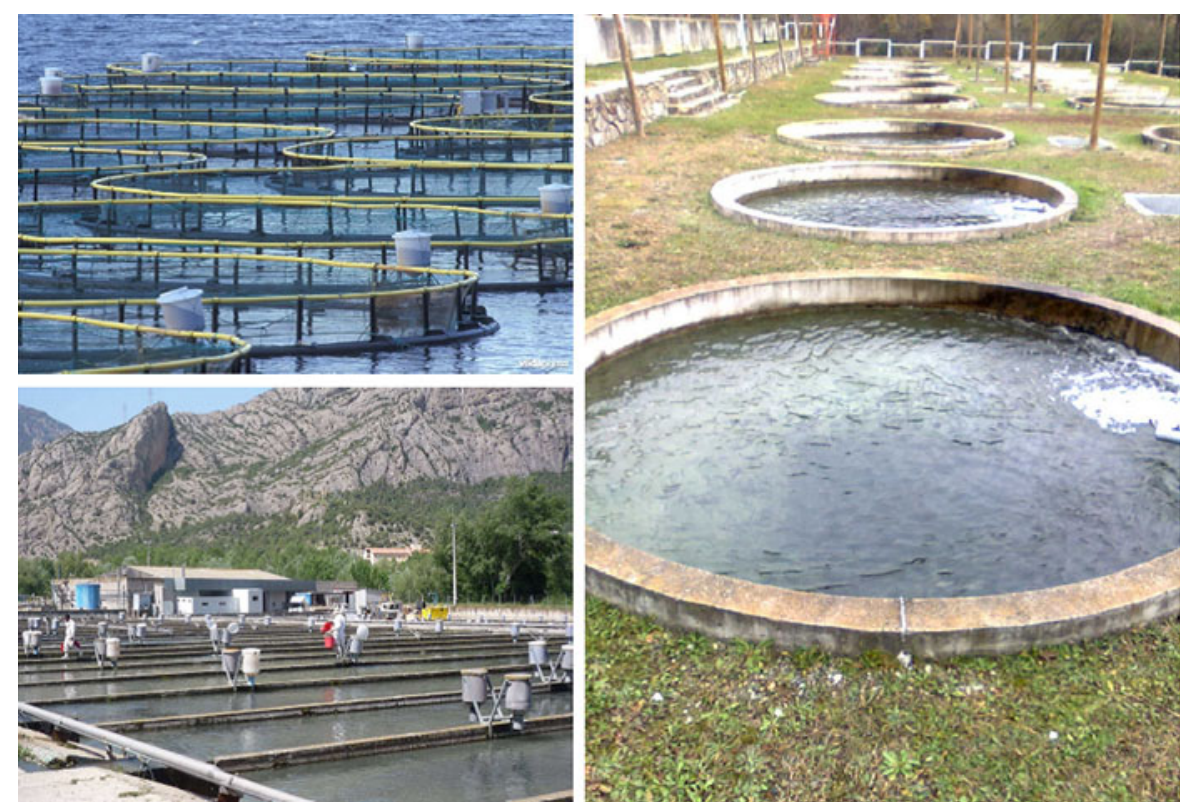
$\mathrm{U}_{\text {opt }}$ swimming becomes unsustainable, stressful, and the ensuing anaerobic metabolism will increase lactate levels, create an oxygen debt and finally cause fatigue (reviewed by Davison 1997, also Palstra et al. 2010d).

Lower cortisol levels in exercised fish may indicate that exercise improves welfare by lowering stress (Huntingford 2010). Exercise may lower stress by reducing levels of aggression or by stimulating neurogenesis, thereby improving spatial learning capacity. An important point of consideration related to stress is the increasing evidence for major differences in individual coping strategies. One is characterized by a proactive, adrenaline-based response and another by a reactive, cortisol-based response. Proactive and reactive fish that were subjected to inflammatory challenge differed in baseline gene expression and also showed diametrically opposite responses to the challenge for $80 \%$ of the genes investigated (MacKenzie et al. 2009). Investigations on how different coping strategies may differ in terms of their physiological response to swimming should be considered in the future.

The final presentation of the workshop gave an excellent example of turning a research concept into a commercial application (Kadri et al. 2010). The optomoter response, the natural response of fish to swim to a moving stimulus, represents an alternative method to induce swimming. A nonmechanical device was designed to elicit the optomoter response, which is currently commercialized by OptoSwim. A paper in this special issue will discuss the results in farmed Atlantic salmon, Salmo salar L.

\section{Swimming in the future}

It can thus be concluded that optimal exercise may have beneficial effects of major importance for aquaculture:

(1) Induced growth by higher feeding efficiency, growth rates, and skeletal muscle mass.

(2) Changes in muscle composition leading to higher flesh quality.

(3) Increased survival by increased robustness or fitness; cardiovascular and respiratory performance, mitochondrial densities, and muscle tissue capillarization.
(4) Increased welfare by lowered stress due to reduced aggressive interactions and stimulation of neurogenesis.

(5) Stimulation of immune status: exercise as a preventive health measure.

(6) Reproduction control: triggering lipid mobilization, delay of sexual maturation, prevention of precocious maturation, and extension of the growth period.

This last session of the FitFish workshop "A role for exercise in improving welfare in sustainable aquaculture" was organized in collaboration with COST: European collaboration in the field of scientific and technical research, action 867: Welfare of fish in European aquaculture, which was introduced by Dr. Sunil Kadri (Optoswim Technologies and University of Glasgow). This session consisted of four sub-sessions to discuss: (1) Exercise in aquaculture production, (2) Quality and nutrition/energy requirements of exercising fish, (3) Exercise and welfare, and (4) The future of FitFish.

In sub-session 1, a practical example of artificially induced exercise in Atlantic salmon was presented by Dr. Neill Herbert (University of Auckland). Opportunities for using robot fish to lead schools of fish were presented by Dr. Claudio Rossi (Universidad Politécnica de Madrid). In sub-session 2, aspects of muscle quality in exercised rainbow trout were presented by Dr. Richard Rasmussen (Technical University of Denmark). Sub-session 3 was already covered by presentations of invited speakers Dr. Harald Takle (Nofima Marin) and Dr. Felicity Huntingford (University of Glasgow).

In sub-session 4, a FitFish network was established by the participants. It was decided that future opportunities for more regular meetings as well as collaborations would be explored. The authors will edit the book Swimming Physiology of Fish that will be published by Springer in 2012 .

\section{Selected FitFish papers in this special FISH issue}

This special issue of Fish Physiology and Biochemistry includes 7 papers that cover topics that were presented and discussed at the FitFish workshop. Makiguchi et al. (2011) present their EMG telemetry studies on upstream migration of chum salmon in the 
Toyohira River, Hokkaido, Japan. Insights into the temporal progression in migratory status and sexual maturation in downstream migrating silver eels in the River Rhine are presented by Palstra et al. (2011). Webb and Cotel (2011) assess possible effects of fish culture systems on fish swimming, specifically the role of stability in turbulent flows. Tudorache et al. (2011) show that optimal swimming speeds reflect preferred swimming speeds in brook charr (Salvelinus fontinalis Mitchill, 1874). Herbert et al. (2011) show that a moving light stimulus elicits a sustained swimming response in farmed Atlantic salmon (Salmo salar L). A paper by Brown et al. (2011) answers the question if swimming fish always grow fast on basis of the magnitude and physiology of exercise-induced growth in juvenile New Zealand yellowtail kingfish, Seriola lalandi. This special issue is completed with Dr. JohnVideler's view on novel fish farming techniques based on breeding processes in the wild: Toward sustainable use of fish white muscle as meat (Videler 2011).

Acknowledgments The authors would like to thank the invited speakers for the FitFish workshop: H. Ueda, D. Righton, G. van den Thillart, P. Sebert, J-M Weber, J. F. Steffensen, G. Claireaux, B. Pelster, A. Krasnov, H. Takle, S. Kranenbarg, J. Videler, P. Webb, C. Tudorache, F. Huntingford, and S. Kadri. We also would like to thank our participants in the local organizing committee Y. Vraskou, L. Magnoni, R. Marín-Juez, D. Crespo, and M. Rovira, our invited chairmen M.S. Lowery, J. Kieffer, H. Toften, oral presenters N. Herbert, C. Rossi, R. Rasmussen, and all participants of the workshop. Furthermore, we thank M. Sánchez and M. Gallego of the Societat Catalana de Biologia of the Institut d'Estudis Catalans for their help in organizing the workshop and E. Clavero for designing the FitFish logo. The workshop organization was supported by financial contributions from the Ministerio de Ciencia e Innovación, Spain (AGL201008754-E to J. V. Planas); Loligo Systems; Xarxa de Referència d'R + D+I en Aqüicultura and the Institut d'Estudis Catalans. Finally, we would like to thank COST (European Cooperation in Science and Technology) FA action 867: Welfare of Fish in European Aquaculture, for participating in the financial support of some of its members. Research on the swimming physiology of rainbow trout and zebrafish at the University of Barcelona was supported by grants from the Ministerio de Ciencia e Innovación, Spain, (CSD2007-0002 and AGL2009-07006) to J. V. Planas. A. P. Palstra was supported by a Marie Curie IntraEuropean Fellowship from the European Commission (REPRO-SWIM) with Grant Agreement number 219971.

Open Access This article is distributed under the terms of the Creative Commons Attribution Noncommercial License which permits any noncommercial use, distribution, and reproduction in any medium, provided the original author(s) and source are credited.

\section{References}

Aarestrup K, Økland F, Hansen MM, Righton D, Gargan P, Castonguay M, Bernatchez L, Howey P, Sparholt H, Pedersen MI, McKinley R (2009) Oceanic spawning migration of the European eel (Anguilla anguilla). Science 325:1660

Adams CE, Huntingford FA, Krpal J, Jobling M, Burnett SJ (1995) Exercise, agonistic behaviour and food acquisition in Arctic charr, Salvelinus alpinus. Environ Biol Fishes 43:213-218

Altringham JD, Ellerby DJ (1999) Fish swimming: patterns in muscle function. J Exp Biol 202:3397-3403

Brown EJ, Bruce M, Pether S, Herbert NA (2011) Do swimming fish always grow fast? Investigating the magnitude and physiological basis of exercise-induced growth in juvenile New Zealand yellowtail kingfish, Seriola lalandi. Fish Physiol Biochem (this issue)

Bugeon J, Lefevre F, Fauconneau B (2003) Fillet texture and muscle structure in brown trout (Salmo trutta). Aquacult Res 34:1287-1295

Claireaux G (2010) Swimming performance as an indicator of robustness in fish. In: Proceedings of the FitFish workshop on the swimming physiology of fish, Barcelona, 2-3 July 2010, p 20

Consuegra S, Johnston IA (2006) Polymorphism of the lysyl oxidase gene in relation to muscle collagen cross-link concentration in Atlantic salmon. Aquac Res 37:1699-1702

Davison W (1997) The effects of exercise training on teleost fish, a review of recent literature. Comp Biochem Physiol A $117: 67-75$

Davison W, Goldspink G (1977) The effect of prolonged exercise on the lateral musculature of the brown trout (Salmo trutta). J Exp Biol 70:1-12

Dohm GL (2002) Exercise effects on muscle insulin signaling and action: invited review: regulation of skeletal muscle GLUT-4 expression by exercise. J Appl Physiol 93:782-787

Duthie G (1987) Observations of poor swimming performance among hatchery-reared rainbow trout, Salmo gairdneri. Environ Biol Fishes 18:309-311

East P, Magnan P (1987) The effect of locomotor activity on the growth of brook charr, Salvelinus fonatinalis Mitchell. Can J Zool 65:843-846

Greer Walker M, Emerson L (1978) Sustained swimming speeds and myotomal muscle function in the trout, Salmo gairdneri. J Fish Biol 13:475-481

Hagen O, Solberg C, Sirnes E, Johnston IA (2007) Biochemical and structural factors contributin to seasonal variation in the texture of farmed atlantic halibut (Hippoglossus hippoglossus) flesh. J Agric Food Chem 55:5803-5808

Hardie DG, Carling D, Carlson M (1998) The AMP-activated/ SNF1 protein kinase subfamily: metabolic sensors of the eukaryotic cell? Annu Rev Biochem 67:821-855 
Herbert NA, Kadri S, Huntingford FA (2011) A moving light stimulus elicits a sustained swimming response in farmed Atlantic salmon, Salmo salar L. Fish Physiol Biochem (this issue)

Holloszy JO (2005) Exercise-induced increase in muscle insulin sensitivity. J Appl Physiol 99:338-343

Huntingford FA (2010) Exercise and welfare. In: Proceedings of the FitFish workshop on the swimming physiology of fish, Barcelona, 2-3 2010 July, p 29

Ibarz T, Felip O, Fernández-Borràs J, Martín-Pérez M, Blasco J, Torrella JR (2011) Sustained swimming improves muscle growth and cellularity in gilthead sea bream. J Comp Physiol 81:209-217

Jellyman D, Tsukamoto K (2010) Vertical migrations may control maturation in migrating female Anguilla dieffenbachia. Mar Ecol Prog Ser 404:241-247

Jessen N, Goodyear LJ (2005) Contraction signaling to glucose transport in skeletal muscle. J Appl Physiol 99:330-337

Johnston IA (1999) Muscle development and growth: potential implications for flesh quality in fish. Aquaculture 177: 99-115

Johnston IA, Moon TW (1980) Endurance exercise training in the fast and slow muscles of a teleost fish (Pollarchius virens). J Comp Physiol 135:147-156

Kadri S, Herbert NA, Huntingford FA (2010) From research concept to commercial application: optoswim technology and finfish aquaculture. In: Proceedings of the FitFish workshop on the swimming physiology of fish, Barcelona, 2-3 July 2010, p 30

Kiessling A, Pickova J, Eales JG, Dosanjh B, Higgs D (2005) Age, ration level, and exercise affect the fatty acid profile of chinook salmon (Oncorhynchus tshawytscha) muscle differently. Aquaculture 243:345-356

Kranenbarg S, Gussekloo SWS, Fiaz AW, van Leeuwen JL (2010) Mechanics and development of the musculoskeletal system in zebrafish. In: Proceedings of the FitFish workshop on the swimming physiology of fish, Barcelona, 2-3 July 2010, p 25

Krasnov A, Castro V, Afanasyev S, Larsson T, Mørkøre T, Takle H (2010) Development of oligonucleotide microarrays and bioinformatic system for aquaculture research. Assessment in studies on exercise physiology of Atlantic salmon. In: Proceedings of the FitFish workshop on the swimming physiology of fish, Barcelona, 2-3 July 2010), p 22

Lighthill MJ (1970) Aquatic animal propulsion of high hydromechanical efficiency. J Fluid Mech 44:265-301

MacKenzie S, Ribas L, Pilarczyk M, Morera Capdevila D, Kadri S, Huntingford FA (2009) Screening for coping style increases the power of gene expression studies. PLoS ONE 4:e5314

Makiguchi Y, Konno Y, Konishi K, Miyoshi K, Ueda H (2011) EMG telemetry studies on upstream migration of chum salmon in the Toyohira River, Hokkaido, Japan. Fish Physiol Biochem (this issue)

McFarland WN, Moss SA (1967) Internal behaviour in fish schools. Science 156:260-262

Merrill GF, Kurth EJ, Hardie DG, Winder WW (1997) AICA riboside increases AMP-activated protein kinase, fatty acid oxidation, and glucose uptake in rat muscle. Am J Physiol Endocrinol Metab 273:E1107-E1112
Miller KM, Schulze AD, Ginther N, Li S, Patterson DA, Farrell AP, Hinch SG (2009) Salmon spawning migration: metabolic shifts and environmental triggers. Comp Biochem Physiol D 4:75-89

Moon TW (2001) Glucose intolerance in teleost fish: fact or fiction? Comp Biochem Physiol B 129:243-249

Moyes CD, West TG (1995) Exercise metabolism of fish. Hochachka PW and Mommsen TP (eds) Biochemistry and molecular biology of fishes, vol IV, chapter 16. Elsevier, The Netherlands, pp 368-392

Onuma TA, Sato S, Katsumata H, Makino K, Hu WW, Jodo A, Davis ND, Dickey JT, Ban M, Ando H, Fukuwaka M, Azumaya T, Swanson P, Urano A (2009a) Activity of the pituitary-gonadal axis is increased prior to the onset of spawning migration of chum salmon. J Exp Biol 212:56-70

Onuma TA, Makino K, Ban M, Ando H, Fukuwaka M, Azumaya T, Swanson P, Urano A (2009b) Elevation of the plasma level of Insulin-like Growth Factor-I with reproductive maturation prior to initiation of spawning migration of Chum salmon. Ann NY Acad Sci 1163:497-500

Onuma TA, Makino K, Katsumata H, Beckman BR, Ban M, Ando H, Fukuwaka M, Azumaya T, Swanson P, Urano A (2009c) Changes in the plasma levels of insulin-like growth factor-I from the onset of spawning migration through upstream migration in chum salmon. Gen Comp Endocrinol 168:356-368

Palstra AP, van den Thillart GEEJM (2010) Swimming physiology of European silver eels (Anguilla anguilla L.): energetic costs and effects on sexual maturation and reproduction. Fish Physiol Biochem 36:297-322

Palstra A, Curiel D, Fekkes M, de Bakker M, Székely C, van Ginneken V, van den Thillart G (2007) Swimming stimulates oocyte development in European eel (Anguilla anguilla L.). Aquaculture 270:321-332

Palstra AP, Schnabel D, Nieveen MC, Spaink HP, van den Thillart GEEJM (2008a) Male silver eels mature by swimming. BMC Physiol 8:14

Palstra AP, van Ginneken V, van den Thillart G (2008b) Cost of transport and optimal swimming speeds in farmed and wild European silver eels (Anguilla anguilla). Comp Biochem Physiol A 151:37-44

Palstra AP, van Ginneken V, van den Thillart G (2009) Effects of swimming on silvering and maturation. In: van den Thillart G, Dufour S, Rankin C (eds) Spawning migration of the European eel. Springer, Netherlands, pp 309-332

Palstra AP, Crespo D, van den Thillart GEEJM, Planas JV (2010a) Saving energy to fuel exercise: swimming suppresses oocyte development and down-regulates ovarian transcriptomic response of rainbow trout Oncorhynchus mykiss. Am J Physiol 299:R486-R499

Palstra AP, Schnabel D, Nieveen M, Spaink H, van den Thillart G (2010b) Swimming suppresses hepatic vitellogenesis in European silver eel as shown by quantitative RT-PCR of the estrogen receptor 1 , vitellogenin 1 and vitellogenin 2 in the liver. Reprod Biol Endocrinol 8:27

Palstra AP, Crespo D, Magnoni LJ, Burgerhout E, Brittijn SA, de Wijze D, Beltran S, Henkel CV, Jansen HJ, Dirks RPH, van den Thillart GEEJM, Spaink HP, Planas JV (2010c) Transcriptomic response to exercise in the Rainbow trout ovary and skeletal muscle as assessed by microarray 
analysis and deep RNA sequencing. In: Proceedings of the FitFish workshop on the swimming physiology of fish, Barcelona, 2-3 July 2010, p 23

Palstra AP, Tudorache C, Rovira M, Brittijn B, Burgerhout E, van den Thillart GEEJM, Spaink HP, Planas JV (2010d) Establishing zebrafish (Danio rerio) as a novel exercise model: swimming economy, swimming-enhanced growth and regulation of muscle growth marker gene expression. PLoS ONE 5(12):e14483

Palstra AP, Guerrero MA, de Laak G, Klein Breteler JPG, van den Thillart GEEJM (2011) Temporal progression in migratory status and sexual maturation in European silver eels during downstream migration. Fish Physiol Biochem (this issue)

Pelster B (2010) Prolonged exercise in developing zebrafish. In: Proceedings of the FitFish workshop on the swimming physiology of fish, Barcelona, 2-3 July 2010, p 24

Pelster B, Bagatto B (2010) Respiration. In: Perry SF, Ekker M, Farrell AP, Brauner CJ (eds) Zebrafish. Fish physiology Volume 29. Academic Press (Elsevier), USA, pp 290-310

Periago MJ, Ayala MD, Lopez-Albors O, Abdel I, Martinez C, Garcia-Alcazar A, Ros G, Gil F (2005) Muscle cellularity and flesh quality of wild and farmed sea bass, Dicentrarchus labrax. Aquaculture 249:175-188

Richards JG, Mercado AJ, Clayton CA, Heigenhauser GJ, Wood CM (2002) Substrate utilization during graded aerobic exercise in rainbow trout. J Exp Biol 205:2067-2077

Righton D, Aarestrup K, Økland F, Gargan P, Poole R, Westerberg H, Feunteun E (2010) To boldly go: Results from a satellite tracking programme reveal details of the oceanic migration of European eels. In: Proceedings of the FitFish workshop on the swimming physiology of fish, Barcelona, 2-3 July 2010), p 15

Scaion D, Sébert P (2008) Glycolytic fluxes in European silver eel, Anguilla anguilla: sex differences and temperature sensitivity. Comp Biochem Physiol A 151:687-690

Sébert P (2010) Pressure effects on European eel muscle metabolism and swimming. In: Proceedings of the FitFish workshop on the swimming physiology of fish, Barcelona, 2-3 July 2010), p 17

Sébert M-E, Amerand A, Vettier A, Weltzien FA, Pasqualini C, Sébert P, Dufour S (2007) Effects of high hydrostatic pressure on the pituitary-gonad axis in the European eel, Anguilla anguilla (L.). Gen Comp Endocrinol 153:289-298

Sébert M-E, Legros C, Weltzien F-A, Malpaux B, Chemineau P, Dufour S (2008) Melatonin activates brain dopaminergic systems in the eel with an inhibitory impact on reproductive function. J Neuroendocrinol 20:917-929

Sébert P, Scaion D, Belhomme M (2009) High hydrostatic pressure improves the swimming efficiency of European migrating silver eel. Resp Physiol Neurobiol 165:112-114

Steffensen JF (2010) A model of oxygen conditions in a school of fish based on experimental respirometry. In: Proceedings of the FitFish workshop on the swimming physiology of fish, Barcelona, 2-3 July 2010, p 19

Takle H, Castro V, Helland S, Kristensen T, Claireaux G, Helgerud J, Farrell T, Krasnov A, Grisdale-Helland B (2010) Exercise training to improve performance and robustness of Atlantic salmon (Salmo salar). In: Proceedings of the FitFish workshop on the swimming physiology of fish, Barcelona, 2-3 July 2010, p 21
Taranger GL, Carrillo M, Schulz RW, Fontaine P, Zanuy S, Felip A, Weltzien FA, Dufour S, Karlsen Ø, Norberg B, Andersson E, Hansen T (2010) Control of puberty in farmed fish. Gen Comp Endocrinol 165:483-515

Totland GK, Kryvi H, Jødestøl KA, Christiansen EN, Tangerås A, Slinde E (1987) Growth and composition of the swimming muscle of adult Atlantic salmon (Salmo salar L.) during long-term sustained swimming. Aquaculture 66:299-313

Tudorache C, Palstra AP, O'Keefe RA, Benfey TJ, Brittijn SA, Burgerhout E, van den Thillart GEEJM, Spaink HP, Planas JV (2010a) Fish exercise methodologies for aquaculture research - an integration of swimming behaviour and physiology. In: Proceedings of the FitFish workshop on the swimming physiology of fish, Barcelona, 2-3 July 2010, p 28

Tudorache C, O'Keefe RA, Benfey TJ (2010b) The effect of temperature and ammonia exposure on swimming performance of brook charr (Salvelinus fontinalis). Comp Biochem Physiol A 156:523-528

Tudorache C, O'Keefe RA, Benfey TJ (2011) Optimal swimming speeds reflect preferred swimming speeds of brook charr (Salvelinus fontinalis Mitchill, 1874). Fish Physiol Biochem (this issue)

Ueda H (2010) Physiological mechanism of homing migration in salmonids. In: Proceedings of the FitFish workshop on the swimming physiology of fish, Barcelona, 2-3 July 2010, p 14

Ueda H (2011) Physiological mechanism of homing migration in Pacific salmon from behavioral to molecular biological approaches. Gen Comp Endocrinol 170:222-232

Van den Thillart G (2010) Swimming energetics of migrating silver eel. In: Proceedings of the FitFish workshop on the swimming physiology of fish, Barcelona, 2-3 July 2010, p 16

van den Thillart G, van Ginneken V, Körner F, Heijmans R, van der Linden R, Gluvers A (2004) Endurance swimming of European eel. J Fish Biol 65:1-7

Van der Meulen T, Schipper H, van den Boogaart JGM, Huising MO, Kranenbarg S, van Leeuwen JL (2006) Endurance exercise differentially stimulates heart and axial muscle development in zebrafish (Danio rerio). Am J Physiol Regul Integr Comp Physiol 291:R1040-R1048

van Ginneken V, Antonissen E, Muller UK, Booms R, Eding E, Verreth J, van den Thillart G (2005) Eel migration to the sargasso: remarkably high swimming efficiency and low energy costs. J Exp Biol 208:1329-1335

Videler JJ (2010) Biomechanical and ecological approaches to fit fish: towards sustainable use of fish white muscle as meat. In; Proceedings of the FitFish workshop on the swimming physiology of fish, Barcelona, 2-3 July 2010, p 26

Videler JJ (2011) Novel fish farming techniques based on breeding processes in the wild: towards sustainable use of fish white muscle as meat. Fish Physiol Biochem (this issue)

Webb PW (2010) Assessing possible effects of fish-culture systems on fish swimming: the role of stability in turbulent flows. In: Proceedings of the FitFish workshop on the swimming physiology of fish, Barcelona, 2-3 July 2010, p 27 
Webb PW, Cotel A (2011) Assessing possible effects of fishculture systems on fish swimming: the role of stability in turbulent flows. Fish Physiol Biochem (this issue)

Weber, J-M (2010) Fuel metabolism: How do fish cope with exercise and hypoxia? In: Proceedings of the FitFish workshop on the swimming physiology of fish, Barcelona, 2-3 July 2010, p 18

Weber J-M, Haman F (1996) Pathways for metabolic fuels and oxygen in high performance fish. Comp Biochem Physiol 113A:33-38
Weltzien F-A, Sébert M-E, Vidal B, Pasqualini C, Dufour S (2009) Dopamine inhibition of eel reproduction. In: van den Thillart G, Dufour S, Rankin C (eds) Spawning migration of the European eel. Springer, Netherlands, pp 201-228

West TG, Arthur PG, Suarez RK, Doll CJ, Hochachka PW (1993) In vivo utilization of glucose by heart and locomotory muscles of exercising rainbow trout (Oncorhynchus mykiss). J Exp Biol 177:63-79

Wilson RP (1994) Utilization of dietary carbohydrate by fish. Aquaculture 124:67-80 